\title{
Learning science from practice
}

\author{
Paul Opdam
}

Received: 13 April 2010/Accepted: 17 April 2010/Published online: 9 May 2010

(C) Springer Science+Business Media B.V. 2010

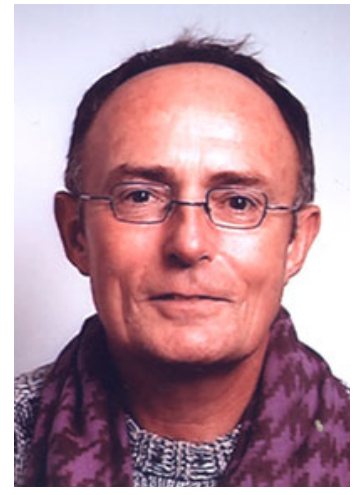

For about a decade researchers in landscape ecology (and other environmental sciences) have been raising the issue of insufficient impact of our science in increasing societal awareness and decision making. Several analyses showed that available knowledge was not used in local landscape planning (Termorshuizen et al. 2007) and in managing conservation sites (Pullin et al. 2004). Although insufficient accessibility of knowledge to practitioners is undoubtedly one of the causes, more fundamental causes exist (Yli-Pelkonen and Niemelä 2006). For example, reserve selection tools may not be appropriate to tackle the questions that managers have, particularly not in landscapes

P. Opdam ( $\square)$

ALTERRA-Research Institute, Wageningen University

Research Center, Droevendaalse Steeg 3,

6708 PB Wageningen, The Netherlands

e-mail: paul.opdam@wur.nl where land for conservation is scarce (Prendergast et al. 1999). Journals are packed with papers proposing more and more sophisticated decision support tools and assessment models, often without any specification of the decision process which is supposed to be supported. Most models are linear models which "can only provide partial conservation solutions because they describe positivist, biologically focused solutions to what are normative, complex conservation problems typically driven by social and economic issues" (Knight et al. 2006). Cash et al. (2003) proposed that the effectiveness of knowledge transfer is determined by three characteristics of knowledge: credibility, saliency and legitimacy. It seems that scientists tend to invest most of their time in improving the credibility (accuracy) of their models, instead of the saliency (what can be done with it in a particular context of problem solving?) and legitimacy (does the knowledge recognize the interests and values of potential users?).

Several papers proposed to build bridges between landscape ecology and landscape planning (Opdam et al. 2002; Leitão and Ahern 2002; Termorshuizen et al. 2007) and between landscape ecology and sustainable development (Potschin and Haines-Young 2006; Wu 2006; Naveh 2007; Opdam 2007; Gardner et al. 2008; Termorshuizen and Opdam 2009; Mussachio 2009; Wu 2010). In these papers a common theme is the need to integrating knowledge, both within landscape ecology to converge different lines of research and between landscape ecology and other scientific disciplines, including social and economic sciences. Termorshuizen 
and Opdam (2009) stressed the importance of linking the pattern-process paradigm with the values humans attribute to landscape functioning.

Although improving interdisciplinary integration is necessary for problem solving, it is not enough. Ecological knowledge was reported to be too rigid and prescriptive for problem solving (Theobald et al. 2000), demanding landscape ecologists to explore how the characteristics of their knowledge tools match the needs in the problem solving process. This calls for learning in interaction with practice. Several terms have been proposed to characterize ways of interaction between scientists and practitioners, such as mode II science (Nowotny et al. 2001) and transdisciplinary methods (Fry et al. 2007). There is a growing understanding that, if scientists not only calibrate their tools on scientific evidence but also tune their methods to problem solving in practical cases, scientific knowledge can have a much greater impact. In other words, application should become part of the scientific domain. Knight et al. (2006) made a plea for testing models in practical application to attain higher levels of user value. Nassauer and Opdam (2008) proposed that design could be both a scientific activity and a coproduction by scientists and practitioners of problem solving. Such social learning of mixed science-practice groups can improve skills of practitioners to handle scientific knowledge and tools, and at the same time improve skills of scientists to provide the right knowledge in the right context. Such coproduction of knowledge (i.e. a transdiscplinary approach) becomes even a necessity in cases where collaborative decision making about landscape change has the characteristics of an unstructured ("wicked") problem, in which involved parties deviate in their view on the problem, in the values they claim, and in the solutions that they see as possible and desirable. Such problems cannot be solved by science alone. This calls for rethinking the science-practice relationship, as well as inventing scientific approaches that can handle such situations (Funtowicz and Ravetz 1993).

In this issue, the journal Landscape Ecology starts a new section- "Landscape Ecology in Practice"-to promote studies that address the science-practice interface problem. In the first contribution, Steingröver et al. describe how in coproduction with local farmers and other stakeholders they developed a design method for landscape infrastructure. With this method they supported a collaborative decision process of local stakeholders about improving the capacity of the landscape to regulate natural pest suppression. The paper discusses what was learned, both by scientists and practitioners. It is a nice example of increasing insight into the science-practice interface problem.

The aim of the new section is to learn how to use application in practice as a scientific method, to improve the significance of landscape ecology in society. We welcome manuscripts addressing questions derived from the science-practice interface as it is positioned in this editorial. Manuscripts should meet the prime criteria for good science (original, logic, transparent). Specific guidelines for manuscripts in this new category, Landscape Ecology in Practice, are available at the website of the journal (http://www. springer.com/life+sciences/ecology/journal/10980). We look forward to your contributions!

\section{References}

Cash DW, Clark WC, Alcock F, Dickson MN, Eckly N, Guston DH, Jäger J, Mitchel RB (2003) Knowledge systems for sustainable development. PNAS 100:8086-8091

Fry G, Tress B, Tress G (2007) Integrative landscape research: facts and challenges. In: Wu J, Hobbs R (eds) Key topics in landscape ecology. Cambridge University Press, Cambridge, pp 246-268

Funtowicz SO, Ravetz JR (1993) Science for the post-normal age. Futures 25:739-755

Gardner RH, Jopp F, Cary GJ, Verburg PH (2008) World congress highlights need for action. Landscape Ecol 23:1-2

Knight AT, Cowling RM, Campbell BM (2006) An operational model for implementing conservation action. Conserv Biol 20:408-419

Leitão AB, Ahern J (2002) Applying landscape ecological concepts and metrics in sustainable landscape planning. Landsc Urban Plan 59:65-93

Mussachio L (2009) The scientific basis for the design of landscape sustainability: a conceptual framework for translational landscape research and practice for designed landscapes and the six Es of landscape sustainability. Landscape Ecol 24:993-1013

Nassauer J, Opdam P (2008) Design in science: extending the landscape ecology paradigm. Landscape Ecol 23:633-644

Naveh Z (2007) Landscape ecology and sustainability. Landscape Ecol 22:1437-1440

Nowotny H, Scott P, Gibbons M (2001) Re-thinking science. Knowledge and the public in an age of uncertainty. Blackwell, Malden

Opdam P (2007) Deconstructing and reassembling the landscape system. Landscape Ecol 22:1445-1446

Opdam P, Foppen R, Vos CC (2002) Bridging the gap between ecology and spatial planning in landscape ecology. Landscape Ecol 16:767-779 
Potschin M, Haines-Young R (2006) "Rio + 10", sustainability science and Landscape Ecology. Landsc Urban Plan 75:162-174

Prendergast JR, Quinn RM, Lawton JH (1999) The gaps between theory and practice in selecting nature reserves. Conserv Biol 13:484-492

Pullin AS, Knight TM, Stone DA, Charman K (2004) Do conservation managers use scientific evidence to support their decision-making. Biol Conserv 119:245-252

Termorshuizen J, Opdam P (2009) Landscape services as a bridge between landscape ecology and sustainable development. Landscape Ecol 24:1037-1052

Termorshuizen JW, Opdam P, Van den Brink A (2007) Incorporating ecological sustainability in landscape planning. Landsc Urban Plan 79:374-384
Theobald DM, Hobbs NT, Bearly T, Zack JA, Shenk T, Riebsame WE (2000) Incorporating biological information in local land use decision making: designing a system for conservation planning. Landscape Ecol 15:35-45

Wu JG (2006) Landscape ecology, cross-disciplinarity, and sustainability science. Landscape Ecol 21:1-4

Wu J (2010) Urban sustainability: an inevitable goal of landscape research. Landscape Ecol 25:1-4

Yli-Pelkonen V, Niemelä J (2006) Use of ecological information in urban planning: Experiences from the Helsinki metropolitan area. Finl Urban Ecosyst 9:211-226 